\title{
El relato digital (digital storytelling) como elemento narrativo en el ámbito educativo
}

\author{
Saulius Rosales-Statkus ${ }^{1}$ \\ Universidad de Alicante \\ Rosabel Roig-Vila ${ }^{2}$ \\ Universidad de Alicante
}

Resumen: El relato es una de las formas más antiguas de transferencia de conocimiento y una capacidad del ser humano que la psicología considera una forma de pensamiento. Si bien la escuela formal no se declina por usar el relato como un vehículo de transferencia de conocimiento, éste es una herramienta útil de enseñanza que permite a los alumnos utilizar sus habilidades y conocimientos, ya que siempre que se cuenta una historia, el oyente explora nuevos mundos y escenarios, al tiempo que desarrolla habilidades de pensamiento crítico para conectarlos a su propio mundo y experiencias. El Relato Digital es una expresión moderna del antiguo arte de contar historias que toma su estructura y elementos del relato tradicional, y que, al incluir la tecnología multimedia, ha aumentado su dimensión pragmática en la educación. Es un arte que permite a los alumnos disfrutar del montaje de un producto multimedia para compartir una historia. Al hacer uso de las nuevas tecnologías que facilitan la conexión, comunicación y colaboración con otras personas en todo el mundo, el Relato Digital permite establecer un puente entre la educación y la tecnología, válido en cualquier tema de estudio y se perfila como una herramienta efectiva para el desarrollo de las Competencias del Siglo XXI.

Palabras clave: Competencias del Siglo XXI, Web 2.0, Multimedia, vídeo.

Abstract: Storytelling is one of the most ancient forms of knowledge transfer and a human capacity considered by psychology as a form of thinking. While formal school doesn't opt to use storytelling as a vehicle to transfer knowledge, this is a useful teaching tool that allows students to use their skills and knowledge, and that whenever a story is told, the listener explores new worlds and scenarios, while developing critical thinking skills to connect them to its own world and experiences. Digital Storytelling is a modern expression of the ancient art of storytelling that takes its structure and elements of the traditional tale, and that by including multimedia technology, has increased its pragmatic dimension in education. It is an art that allows students to enjoy a multimedia product assembly to share a story. By making use of new technologies that facilitate networking, communication and collaboration with others worldwide, Digital Storytelling allows to establish a bridge between education and technology, valid on any topic and is emerging as an effective tool for the development of the 21 st Century skills.

Keywords: 21 st Century skills, Web 2.0, Multimedia, video.

\section{Introducción}

Actualmente hay un creciente interés por definir y poner en práctica nuevas metodologías y estándares educativos diseñados para facilitar el desarrollo de competencias necesarias en el Siglo XXI. Se habla de nuevas alfabetizaciones orientadas a satisfacer las necesidades de formación y preparación de los individuos para desenvolverse con éxito en una sociedad del conocimiento, cada vez más tecnológica y globalizada, en la que hay que saber lidiar con nuevas situaciones,

\footnotetext{
${ }^{1}$ Saulius Rosales-Statkus, miembro del Grupo de Investigación EDUTIC-ADEI (VIGROB-0039). Doctor en Investigación Educativa, Desarrollo Curricular y Profesional (Universidad de Alicante), Magíster en Educación, mención Procesos de Aprendizaje (Universidad Católica Andrés Bello), y Licenciado en Computación (Universidad Central de Venezuela). Profesor e investigador en Tecnología Educativa.

${ }^{2}$ Doctora en Pedagogía, Directora del ICE de la Universidad de Alicante, directora de NAER-Journal of New Approaches in Educational Research,http://naerjournal.ua.es, directora del Grupo de Investigación EDUTIC-ADEI (VIGROB-0039), Profesora Titular de Universidad, Dpto. de Didáctica General y Didácticas Específicas, Universidad de Alicante.
} 
nuevas tecnologías, interpretar y presentar la información de forma acertada, desenvolverse correctamente en entornos multiculturales, atender a la diversidad, solucionar problemas, tener conciencia cívica y explotar las habilidades de pensamiento de orden superior (Bocconi et al., 2012; Consortium Horizon Project, s.f.; Dogan, 2007; ISTE, 2011; Karakoyun, 2014; Partnership for 21st Century Skills, 2012).

Para todo esto, distintos consorcios y entidades han definido estándares de formación y evaluación que se ajustan a todos los niveles educativos y que consideran entornos de aprendizaje formales e informales (Bocconi et al., 2012; Johnson et al., 2013; Johnson et al., 2014). El Relato Digital se encuentra en consonancia con estos estándares y formas de evaluar el progreso de los estudiantes, y se perfila como una herramienta efectiva para el desarrollo de las Competencias del Siglo XXI (Gregori, 2007; Robin, 2008).

Con la definición de estos estándares se pretende hacer un cambio en los métodos de enseñanza para satisfacer las necesidades educativas y propiciar la inclusión de las TIC en la educación. A pesar de los esfuerzos de quienes promueven este cambio, sigue existiendo una brecha tecnológica importante entre los centros educativos y el entorno de los estudiantes (Dogan, 2007). Aunado a esto, la formación de los profesores no termina de consolidarse en el desarrollo de las competencias tecnológicas y muchos docentes carecen de la confianza necesaria para implementar este tipo de herramientas (Galstaun et al., 2011).

Si bien los Relatos Digitales han sido usados en distintos ambientes desde hace más de treinta años (por ejemplo con fines sociales), su inclusión en el campo educativo aún está apenas comenzando (Duveskog et al., 2012; Rosenthal, 2009; Porter, 2013; Robin, 2006).

\section{La narrativa o el relato como vehículo cultural y del conocimiento}

El relato es una de las formas más antiguas de transferencia de conocimiento. Es un bien de todos los humanos, que abarca todas las culturas y épocas, y al que se puede referir como "el arte de transmitir acontecimientos a través de palabras, imágenes y sonidos, a menudo por la improvisación o el embellecimiento" (Duveskog et al., 2012). Sin importar el medio utilizado, el relato es una herramienta poderosa de transmisión de conocimientos, cultura, perspectivas y puntos de vista (Rosenthal, 2009). Es un recurso que los padres suelen usar para enseñarle a sus hijos temas que van desde los valores hasta cualquier tipo de conocimiento (Duveskog et al., 2012).

Las historias son tan antiguas como la gente y muy importantes para nuestros espíritus, mentes y el progreso humano. Convertirse en buenos narradores nos da poder personal para guiar, motivar, entretener, educar, inspirar e influenciar a los demás mediante una historia ingeniosa (Porter, 2008).

Contar cuentos es el arte interactivo de usar las palabras y acciones para revelar los elementos e imágenes de una historia, al tiempo que se motiva la imaginación de los oyentes. El relato es interactivo, usa palabras, usa distintas acciones como la vocalización, movimientos físicos y/o gesticulaciones para presentar una historia. Todos estos elementos permiten a los alumnos utilizar sus habilidades y conocimientos, ya que siempre que se cuenta una historia, el oyente explora nuevos mundos y escenarios, al tiempo que desarrolla habilidades de pensamiento crítico para conectarlos a su propio mundo y experiencias (Rosenthal, 2009).

La narrativa personal toma su forma según cómo el autor presta atención y siente los eventos. Son muchos los elementos que contribuyen a la indeterminación de 
toda narrativa personal. A medida que experimentamos la vida, nuestras percepciones son filtradas a través de nuestra perspectiva cultural y física, así como nuestra memoria selectiva (Davis A., 2005).

Rodríguez y Londoño (2009) citan a Schank, entre otros, como un defensor de la importancia de las historias y relatos como forma compleja de almacenamiento en la memoria y de la manera en que enfrentamos las situaciones a diario. Igualmente indican que ha llegado a proponer metodologías de enseñanza y aprendizaje basadas en la construcción de historias.

Asimismo, explica Londoño (2012) el interés renovado que hay por la narrativa que, al ser reconocida como un mecanismo organizador de la experiencia y una forma de inteligencia, permite procesar y dotar de significado las experiencias propias, prolongar la memoria del individuo, y "enfrentar situaciones o problemáticas de la vida cotidiana al procesar individualmente las vivencias, organizarlas, explicarlas y, en definitiva, encontrarles sentido" (Londoño, 2012, pág. 21).

"La narración es una capacidad del ser humano que la psicología considera una forma de pensamiento (Bruner, 1986). La modalidad narrativa del pensamiento, junto a la lógico-científica, o analítica, son las dos formas de funcionamiento cognitivo con las que el individuo da sentido a la experiencia, de forma que no sólo es capaz de comprobar hipótesis o dar explicaciones lógicas, sino de crear mundos posibles, imaginarios, con los que construir su propio universo real". (Ramírez; Sotomayor, 2012, pág. 54)

El relato es un método natural de la comunicación humana y prevalece en todos los aspectos de la interacción social humana (Xu et al., 2011). Citando a varios autores, Londoño (2012) indica que es un mecanismo para relacionarse con los demás, transmitir saberes, reflexiones o experiencias, sentirse parte de una comunidad y construir la identidad. Aseguran Ramírez y Sotomayor (2012) que, con el relato, el ser humano se ha construido como individuo y como ser social.

El relato es una herramienta útil de enseñanza, no solo para lo relacionado con el lenguaje, sino también en ciencias (Rosenthal, 2009); sin embargo, la escuela formal no se declina por usar el relato como un vehículo de transferencia de conocimiento, y menos como un vehículo para la pedagogía constructivista moderna auto-dirigida y centrada en el estudiante (Duveskog et al., 2012).

\section{¿Qué son los Relatos Digitales (Digital Storytelling)?}

“... El Relato Digital combina lo mejor de dos mundos: el "mundo nuevo" del vídeo, las imágenes y el arte digital, y el "mundo viejo” de contar historias” (William Dauphinais citado en Pratt, 2010, p. 3).

El relato digital es una expresión moderna del antiguo arte de contar historias. En él, se combinan elementos multimedia como imágenes, sonido, música y otros para presentar una historia (Xu et al., 2011). Es un arte que es tanto personal como educativo y el proceso de construir un relato digital puede ser difícil de definir, porque no se basa en una fórmula única, y esto se debe, básicamente, a que el relato surge de la visión personal, de cómo el creador se involucra personalmente con la información y la historia (Davidson; Porter, 2005). En el ámbito educativo, es un arte que permite 
a los alumnos de todas las edades disfrutar del montaje de un producto multimedia para compartir una historia (Microsoft Corporation, 2010).

El Relato Digital tiene distintos usos (Miller, 2013):

- Algunos individuos y organizaciones consideran a la narración digital como una especie de periodismo en primera persona, una técnica para relatar historias de la vida real, ilustrado por diversos tipos de material visual.

- Otros lo ven como una herramienta educativa para alfabetizar en multimedia y habilidades narrativas para niños en edad escolar y para animarlos al aprendizaje.

- Y otros definen la narrativa digital en un sentido más amplio, menos especializado y consideran que es el uso de tecnología digital interactiva para contar historias participativas y que llaman a la inmersión. Estas historias pueden ser obras de ficción o no, y pueden ser dirigidas a un público general o grupos especializados. Además, pueden ser destinadas exclusivamente al entretenimiento o se pueden utilizar con fines pragmáticos, como la educación, la formación, la promoción o información. Pero siempre ofrecen algún grado de entretenimiento.

Algunos autores definen el Relato Digital como un relato que se sustenta en la tecnología digital y las redes como medio o método de expresión (Xu et al., 2011). Otros lo definen como un texto multimedia formado por imágenes fijas complementadas con una narración que relata una historia. Los Relatos Digitales pueden tener varias formas, ya sea imágenes fijas con narración, vídeos, documentales, creaciones profesionales, o producciones estudiantiles. En resumen, pueden ser cualquier cosa que utilice tecnología digital para construir una narrativa (Sylvester; Greenidge, 2009). Pero para muchos, una definición precisa del término es difícil de determinar, ya que el significado del Relato Digital depende de factores como el contexto, la audiencia, el propósito y la postura filosófica del autor y del público (Snelson; Sheffield, 2009).

En realidad hay muchas definiciones de "Relato Digital" (Digital Storytelling), pero en general hacen referencia a combinar el arte de contar cuentos con una variedad de elementos digitales multimedia como imágenes, audio, vídeo y música para presentar la información de un tema específico. Como sucede con los relatos tradicionales, los digitales suelen tener un punto de vista particular. Se pueden usar para contar relatos personales, eventos históricos, o como una forma de enseñar un tópico en particular (Robin, 2006; Gregori, 2007).

Para Gregori (2007), el Relato Digital toma su estructura y elementos del relato tradicional, pero ha enriquecido considerablemente su formato, presentación y modo de distribución, con la inclusión de la tecnología multimedia, lo que ha hecho aumentar su dimensión pragmática.

El Relato Digital ofrece más ventajas que el relato tradicional, aunque la mayoría son las mismas (Duveskog et al., 2012): 
- Provee una plataforma neutra en la que los estudiantes se sienten más seguros para compartir sus historias, incluso si se están tratando temas delicados.

- Ofrece una variedad de formas para que las distintas personas puedan expresar sus historias de acuerdo a sus gustos.

- Aumenta la motivación de los autores.

- Provee un alcance extendido de las historias, incluso fuera de su comunidad, permitiendo a la audiencia aprender de dichas historias.

- Mejora la creatividad, imaginación y concentración más que el relato tradicional.

- Conserva la tradición oral, pudiendo ser almacenado para próximas generaciones.

Tabla 1: Ventajas del Relato Digital y el tradicional (Duveskog et al., 2012)

\begin{tabular}{|c|c|}
\hline $\begin{array}{l}\text { Relato tradicional (basado en Woodhouse, } \\
\text { 2008, citado por Duveskog et Al., 2012) }\end{array}$ & Relato Digital \\
\hline $\begin{array}{l}\text { Comparte historias de éxito y desarrolla el } \\
\text { sentido de comunidad }\end{array}$ & $\begin{array}{l}\text { Comunidad más amplia } \\
\text { Riqueza de historias más amplia }\end{array}$ \\
\hline $\begin{array}{l}\text { Explora roles personales y le da sentido a sus } \\
\text { vidas }\end{array}$ & Similar al relato tradicional \\
\hline $\begin{array}{l}\text { Mejora la creatividad, imaginación y la } \\
\text { concentración }\end{array}$ & $\begin{array}{l}\text { Mejora los procesos creativos y la } \\
\text { concentración }\end{array}$ \\
\hline $\begin{array}{l}\text { El uso de la imaginación permite recordar las } \\
\text { historias }\end{array}$ & Memoria ampliada \\
\hline $\begin{array}{l}\text { Mejora el pensamiento crítico y las } \\
\text { habilidades de escucha }\end{array}$ & Similar al relato tradicional \\
\hline \multirow[t]{2}{*}{ Mantiene la tradición oral } & $\begin{array}{l}\text { Provee una plataforma virtual para la } \\
\text { tradición oral }\end{array}$ \\
\hline & $\begin{array}{l}\text { Aumenta la motivación, creación de historias } \\
\text { (Nuutinen et al., 2010, citado por Duveskog } \\
\text { et al., 2012) }\end{array}$ \\
\hline
\end{tabular}

A pesar del interés que puede haber actualmente en la tecnología multimedia, el Relato Digital no es un concepto nuevo (Robin, 2006). Con el avance de la tecnología, a partir de los años 90 la posibilidad de adquirir a precios módicos videocámaras, escáneres, programas para la edición de imágenes y vídeo, así como ordenadores personales, ayudó a que presentar una historia combinando elementos gráficos y sonido digitales fuera una opción ampliamente accesible (Davis, 2005). En realidad, los relatos contados a través de herramientas digitales se remontan a los primeros días de los ordenadores personales y las primeras redes (Alexander; Levine, 2008), y esta corriente continúa gracias a que ahora prácticamente cualquiera puede 
disponer de un ordenador con el software adecuado (Marcuss, 2003). Esto involucra, incluso, a personas de bajos ingresos, jóvenes y tercera edad (Davis A., 2005).

Anteriormente, en los años 80, Lambert y Atchley impulsaron el movimiento del Relato Digital creando el Centro para el Relato Digital (CDS - Center for Digital Storytelling, hoy día conocido como Storycenter), en California. Esto dio un impulso al desarrollo de los Relatos Digitales, unido a la creciente accesibilidad a las herramientas digitales necesarias para construirlos (Robin, 2008).

Al igual que los autores citados en los párrafos anteriores, Miller (2009) expone lo mismo en el ámbito educativo. Miller indica (citando a Robin, 2008) que uno de los factores que ha permitido el crecimiento del uso de los Relatos Digitales en las clases ha sido que las herramientas tecnológicas cada vez son más asequibles y comunes en los centros educativos... Y es que los Relatos Digitales son mayoritariamente conocidos como historias multimodales cortas hechas con equipos económicos que hablan, sobre todo, de experiencias personales (Gregori; Pennock, 2012).

Las nuevas herramientas tecnológicas nos facilitan conectarnos, comunicarnos y colaborar con otras personas en todo el mundo, y esto permite a los Relatos Digitales establecer un puente entre la educación y la tecnología, válido en cualquier tema de estudio. A través de los Relatos Digitales podemos conectarnos con otras personas y conectar a estas personas con nuestras propias experiencias. Además, las historias nos permiten comunicar nuestra perspectiva y percepción. Y, por último, las historias suelen reflejar un esfuerzo colaborativo entre los personajes, sus acciones y puntos de vista. Además, las historias que persisten en el tiempo son susceptibles de reajustes y con esto se logran nuevas perspectivas y cambios en la trama (Rosenthal, 2009). Incluso, en el ámbito educativo, la creación de Relatos Digitales conlleva una fuerte carga de colaboración y respeto, así como otros valores.

Mattheus-DeNatale (2008) indica que a lo largo de la historia, el relato ha sido usado para compartir conocimiento, sabiduría y valores, y que las historias han adoptado distintas formas, según van apareciendo nuevos medios para transmitirlas. El formato que más se ha popularizado en el medio educativo es el de una narración personal breve de éxito ante los obstáculos, el logro de un sueño, rendirle honores a un familiar, o describir un evento (Alexander; Levine, 2008), sin embargo, hay quienes extienden este concepto a otros medios de comunicación digitales, lo cual veremos más adelante.

En tal sentido, una definición bastante envolvente, que reúne los elementos más comunes es, quizás, la que da Pereira (2010) citando a otros investigadores:

"Los Relatos Digitales son cuentos multimedia cortos que causan emoción y aprendizaje (Salpeter, 2005). En un sentido amplio, los Relatos Digitales consisten en una serie de imágenes o vídeos cortos que son combinados con una narración grabada para contar una historia (Bull \& Kadjer, 2004); pueden ser usados para informar, instruir, motivar, demostrar o comunicar una narración personal (Robin, 2008)" (Pereira, 2010, p. 3795).

Explicado de otra manera, el Relato Digital es conocido ampliamente como una forma breve de narrativa, usualmente personal, relatada en primera persona, presentada como un vídeo corto para ser visto en televisión, ordenador o proyectado (Davis, 2005). Y, aunque en ocasiones se pueden incluir trozos de vídeo, se puede crear un Relato Digital sin tener acceso a dispositivos de vídeo (Bull; Kajder, 2004). 
Según el formato más extendido, el que se ajusta a las dos definiciones recién expuestas, hay un cierto rigor en la construcción de un Relato Digital, y es que el guion debe ser de 250 palabras, contar con, aproximadamente, una docena de imágenes, y debe durar dos minutos (BBC Capture Wales/Cipolwg ar Gymru team, 2008). Pratt (2010) habla de un guion de "aproximadamente" 250 palabras, y Matthews-DeNatale (2008), Rance-Roney (2008) y Westman (2012) hablan de vídeos que duran entre 2 y 5 minutos. En realidad las historias generalmente duran unos pocos minutos (Robin, 2006).

Creative Narrations (2009) resume la actividad de un taller de Relatos Digitales de la siguiente forma:

"Durante estos tres días, usted creará un vídeo de uno a tres minutos, a través de un proceso intensivo de desarrollo de guion, recolección de medios, y edición multimedia. Los Relatos Digitales están basados en su propia experiencia relatada a través de su propia perspectiva. Su voz será grabada e integrada con sus fotos, cartas, vídeos caseros y otros elementos" (Creative Narrations, 2009, p. 2).

En una guía de creación de Relatos Digitales, Adobe Systems Incorporated (2008) da especial importancia a la voz del autor que narra la historia al definirla como la pieza central de todo el montaje. La voz del narrador crea un encanto especial mientras desarrolla la historia para generar un ambiente particular que atrapa al público. Estas historias personales están generalmente diseñadas para exaltar las emociones y conectar con los sentimientos de la audiencia.

La entonación, gestos, expresiones y acentos de quien relata la historia, junto con las palabras, la cargan de una emotividad significativa. Si bien los Relatos Digitales permiten al autor controlar las imágenes y sonidos de su presentación, ésta se convierte en un producto "fijo" que dista de la realidad del relato tradicional, que puede variar cada vez que es narrado y permite al autor reconstruirlo cada vez que lo cuenta. El Relato Digital en cambio, por la forma en que está construido, es más difícil de cambiar. Una vez terminado, el narrador ya no es necesario, y el producto queda como un objeto para la reflexión y la crítica (Davis, 2005).

El Relato Digital ofrece oportunidades para expandir la forma de comunicarnos, conectar, aprender, liderar, persuadir y reflexionar sobre nuestras vidas (Pratt, 2010), y puede formar parte de programas de desarrollo, pero debe ser introducido considerando las redes sociales locales y los contextos culturales, para adaptarlo en consecuencia (Tacchi, 2009).

\section{El Relato Digital en la Web 2.0}

El Relato Digital permite la creación de experiencias novedosas de aprendizaje, soportado y extendido por las facilidades que ofrece la Web 2.0. Esto, junto con la creación de contenidos compartidos y las redes sociales, motivan (Robin, 2008; Riesland, 2005) y simplifican a los profesores la integración de la tecnología en el currículo (Pereira, 2010).

Aunque parece que hay un consenso generalizado de que el Relato Digital integra las historias personales significativas con los medios (imágenes, sonidos, textos, etc.), y se han descrito sus características, la definición y propósitos de éstos sigue dependiendo un tanto de la interpretación. Menos claro aún es cómo se está 
usando la tecnología Web 2.0 para dar soporte al Relato Digital (Snelson; Sheffield, 2009).

En tal sentido, gracias a las redes sociales, las historias se pueden convertir en relatos con final abierto, con ramificaciones, híper-enlazados, con múltiples medios (textos, imágenes, sonidos, enlaces, etc.), participativos, exploratorios e impredecibles. El Relato Digital en la Web 2.0 toma todos estos tipos de historias y experimenta una aceleración en su ritmo de creación y participación, al tiempo que aparecen nuevos caminos en el cuento (Alexander; Levine, 2008).

Hay dos elementos claves que distinguen a la Web 2.0: el micro-contenido y las redes sociales. El primero sugiere que los autores pueden crear pequeñas porciones de contenido que expresan una idea o concepto. Debido a las facilidades de creación que ofrece la Web 2.0, el esfuerzo se puede enfocar más en el contenido que en los aspectos técnicos. Con respecto al segundo elemento, las plataformas 2.0 generalmente están estructuradas en función de las personas, ya sea para la creación de contenidos o a través de la asociación de comentarios o discusiones. Este tipo de participación distribuida ofrece la posibilidad de agregar información desde distintos puntos de vista, ya sea como lectores o coautores, y ofrece un entorno novedoso para los Relatos Digitales que, incluso, permite elevar la calidad de los contenidos (Alexander; Levine, 2008).

Los Relatos Digitales en la web 2.0 generalmente van más allá del concepto tradicional promovido por el CDS: pueden representar la historia, la fantasía, un concepto, un rompecabezas, un mensaje, o algo que colinda con la realidad y la ficción (Alexander; Levine, 2008).

Alexander y Levine (2008) proponen algunos principios y prácticas para desarrollar los Relatos Digitales Web 2.0. Éstos hacen referencia a la linealidad de los relatos, la variabilidad en la historia, el trabajo en equipo con personas conectadas a través de la Web, el control de la historia y los juegos de realidad alternativa, y proponen, además, un listado de herramientas Web 2.0 publicado como una página Web en Internet ${ }^{3}$ en el que se hace una recopilación de programas que permiten crear historias controlando secuencias de imágenes, la línea del tiempo, mezcladores de sonido, dibujos animados, collages, etc. (Levine, CogDogRoo - Storytools, 2012) y ésta página, a su vez, enlaza con $\mathrm{otra}^{4}$ en la que se anima a las personas a relatar una historia que puede ser profundamente personal, un viaje, un reporte de un proyecto o, simplemente, un dibujo animado (Levine, 2014).

\section{El Relato Digital en YouTube}

Las estadísticas de YouTube son suficientemente llamativas (Youtube, 2015):

- Más de mil millones de usuarios únicos visitan YouTube cada mes.

- Cada mes se reproducen más de 6000 millones de horas de vídeo en YouTube: casi una hora por cada persona del mundo y un 50\% más que el año anterior.

- Cada minuto se suben 100 horas de vídeo a YouTube.

- El 80\% del tráfico de YouTube procede de fuera de EE. UU.

\footnotetext{
${ }^{3} \mathrm{http} / / / \operatorname{cogdog}$ roo.wikispaces.com/StoryTools

${ }^{4}$ http://50ways.wikispaces.com/
} 
- YouTube tiene versiones locales en más de 70 países y puede navegarse en 76 idiomas diferentes.

- YouTube llega a más adultos de Estados Unidos de edades comprendidas entre los 18 y los 34 años que cualquier televisión por cable.

- Millones de usuarios se suscriben cada día. El número diario de nuevos suscriptores se ha triplicado desde el año anterior, y el número de suscripciones diarias es cuatro veces mayor en comparación con 2012.

- Alrededor del $40 \%$ del tiempo total de visualización de YouTube procede de dispositivos móviles.

- YouTube está disponible en cientos de millones de dispositivos.

Los servicios para compartir vídeos en la Web 2.0 han experimentado un crecimiento explosivo desde la creación de YouTube en 2005. Las historias digitales y el intercambio de vídeos, se ha convertido en una práctica natural (Snelson; Sheffield, 2009). Chapman, citado por Dreon et al. (2011), indica que para el año 2010 la plataforma reproducía más de dos billones de vídeos al día, por lo que se podría decir que "el vídeo viral es la moneda cultural de los jóvenes de hoy día". YouTube, además, ofrece la posibilidad de crear comunidades en torno a los relatos y habilita herramientas para hacer comentarios, valoraciones y respuestas (Snelson; Sheffield, 2009).

Publicar Relatos Digitales educativos atractivos en YouTube puede ser una forma efectiva para comunicarse con los estudiantes adolescentes, y una vía de demostrar la comprensión de la dinámica de cambio constante en la cultura juvenil (Dreon et al., 2011).

\section{A modo de conclusión}

Cuando se crea un Relato Digital, el autor incorpora una imagen de sí mismo que proyecta ante los receptores. Estos receptores se tienen presente mentalmente, ya sea como "lectores ideales" o "lectores reales". "El hecho de compartir un relato en la red hace que éste pueda ser visto por cualquiera" (Herreros, 2012, p. 72), ampliando así, no sólo la audiencia, sino las posibilidades de intercambio de opiniones que pueden ayudar a mejorar la calidad del producto.

\section{Referencias}

Adobe Systems Incorporated. (2008). Digital Storytelling: Digital photography and video guide.

Alexander, B., \& Levine, A. (2008). Web 2.0 Storytelling: Emergence of a new genre. Educause Review, 43(6), 40-56.

BBC Capture Wales/Cipolwg ar Gymru team. (2008). A guide to Digital Storytelling. 
Bocconi, S., Kampylis, P., \& Punie, Y. (2012). Innovating Teaching and Learning Practices: Key Elements for Developing Creative Classrooms in Europe. eLearning Papers(30), 1-13.

Bull, G., \& Kajder, S. (2004). Digital Storytelling in the Language Arts Classroom. Learning \& Leading with Technology, 32(4), 46-49.

Consortium Horizon Project, N. M. (s.f.). About The NMC. Recuperado el 22 de abril de 2010, de NMC sparking innovation, learning \& creativity:

http://www.nmc.org/about

Creative Narrations. (2009). Digital Storytelling Workshop. Preparation packet.

Recuperado el 22 de 04 de 2013, de

http://www.creativenarrations.net/sites/default/files/sample_creative_narration s_dstory_preparation_packet.pdf

Davidson, H., \& Porter, B. (2005). The Art of digital Storytelling. Discovery Education, 12-14.

Davis, A. (2005). Co-authoring identity: Digital storytelling in an urban middle school. THEN(1).

Dogan, B. (2007). Implementation of Digital Storytelling in the Classroom by Teacher Trained in a Digital Storytelling Workshop. Doctoral Dissertation, University of Houston, Faculty of the College of Education, Houston.

Dreon, O., Kerper, R., \& Landis, J. (2011). Digital Storytelling: A Tool for Teaching and Learning in the YouTube Generation. Middle School Journal, 42(5), 4-9.

Duveskog, M., Tedre, M., Islas , C., \& Sutinen, E. (2012). Life Planning by Digital Storytelling in a Primary School in Rural Tanzania. Educational Technology \& Society, 15(4), 225-237.

Galstaun, V., Kennedy-Clark, S., \& Hu, C. (2011). The Impact of TPACK on Preservice Teacher Confidence in Embedding ICT into Curriculum Areas. En ED-Media 2011 World Conference on Educational Multimedia, Hypermedia and Telecommunications. Lisboa.

Gregori, C. (2007). Practical uses of Digital Storytelling. Recuperado el 22 de 04 de 2013, de Universitat de Valencia: http://www.uv.es/gregoric/DIGITALSTORYTELLING/DS_files/DST_15_en e_08_final.pdf

Gregori, C., \& Pennock, B. (2012). Digital storytelling as a genre of mediatized selfrepresentations: an introduction. Digital Education Review, 22.

Herreros, M. (2012). El uso educativo de los relatos digitales personales como herramienta para pensar el Yo (Self). Digital Education Review, 22, 68-79.

ISTE. (2011). ISTE NETS-T: Advancing Digital Age Teaching. US/Canada.

Johnson, L., Adams-Becker, S., Cummins, M., Estrada, V., Freeman, A., \& Ludgate, H. (2013). NMC Horizon Reporta: 2013 K-12 Edition. Austin, Texas: The New Media Consortium. 
Johnson, L., Adams-Becker, S., Estrada, V., \& Freeman, A. (2014). NMC Horizon Report: 2014 Higher Education Edition. Austin, Texas: The New Media Consortium.

Karakoyun, F. (2014). Çevrimiçi ortamda oluşturulan dijital öyküleme etkinliklerine ilişkin öğretmen adaylari ve ilköğretim öğrencilerinin görüşlerinin incelenmesi. Doktora Tezi, Anadolu Üniversitesi Eğitim Bilimleri Enstitüsü, Bilgisayar ve Öğretim Teknolojileri Eğitimi Anabilim Dalı, Eskişehir Türkiye.

Levine, A. (2012). CogDogRoo - Storytools. Recuperado el 23 de 01 de 2014, de http://cogdogroo.wikispaces.com/StoryTools

Levine, A. (2014). 50+ Web Ways to Tell a Story. Recuperado el 23 de 01 de 2014, de http://50ways.wikispaces.com/

Londoño-Monroy, G. (2012). Aprendiendo en el aula: contando y hacienda relatos digitales personales. Digital Education Review, 22, 19-39.

Marcuss, M. (2003). Digital storytelling as a Community Development Strategy. Communities \& Banking, 9-13.

Matthews-DeNatale, G. (2008). Digital Storytelling: Tips and Resources. Simmons College. Boston, MA: Educause Learning Initiative.

Microsoft Corporation. (2010). Tell a Story, Become a Lifelong Learner. Seattle.

Miller, C. (2013). Digital Storytelling: A Creator's Guide to Interactive Entertainment (Segunda ed.). Burlington: Focal Press.

Partnership for 21 st Century Skills. (2012). The Partnership for 21st Century Skills. Recuperado el 12 de 12 de 2013, de http://www.p21.org/

Pereira Coutinho, C. (2010). Storytelling as a Strategy for Integrating Technologies into the Curriculum: an Empirical Study with Post-Graduate Teachers. Proceedings of Society for Information Technology \& Teacher Education International Conference 2010, (págs. 3795-3082).

Porter, B. (2008). The Art of Digital Storytelling: Part I. Becoming 21st-Century StoryKeepers. Creative Educator, 1(4), 14-16.

Porter, B. (2013). Digitale: Scoring Guides. Recuperado el 25 de 04 de 2014, de http://digitales.us/evaluating-projects/scoring-guides

Pratt, S. (2010). Digital Storytelling Guide. University of Wollongong.

Ramírez-Verdugo, M., \& Sotomayor Sáez, M. (2012). El valor de una historia digital en el contexto europeo de aprendizaje integrado a través de lengua y contenido (CLIL). Digital Education Review, 22, 52-67.

Rance-Roney, J. (2008). Digital Storytelling for Language and Culture Learning. Essential Teacher, 5(1), 29-31.

Riesland, E. (2005). Visual Literacy and the Classroom. Recuperado el 29 de 04 de 2013, de Johns Hopkins University. School of Education. New Horizons for 
Learning:

http://education.jhu.edu/PD/newhorizons/strategies/topics/literacy/articles/vis ual-literacy-and-the-classroom/

Robin, B. (2006). The Educational Uses of Digital Storytelling. In C. Crawford et al. (Eds.), Proceedings of Society for Information Technology \& Teacher Education International Conference 2006, (págs. 709-716). Chesapeake.

Robin, B. (2008). Digital Storytelling: A Powerful Technology Tool for the 21st Century Classroom. Theory Into Practice, 47(3), 220-228.

Rodríguez I., J. L., \& Londoño M., G. (2009). Los relatos digitales y su interés educativo. Educação, Formação \& Tecnologias, 2(1), 5-18.

Rosenthal Tolisano, S. (2009). How-to-guide: digital Storytelling, Tools for Educators.

Snelson, C., \& Sheffield, A. (2009). Digital Storytelling in a Web 2.0 World. Technology, Colleges \& Community (TCC) Worldwide Online Conference, 2009, págs. 159-167. Manoa.

Sylvester, R., \& Greenidge, W.-I. (2009). Digital Storytelling: Extending the Potential for Struggling Writers. The Reading Teacher, 63(4), 284-295.

Tacchi, J. A. (2009). Finding a voice : digital storytelling as participatory development in Southeast Asia. En J. Hartley, \& K. McWilliam, Story circle : digital storytelling around the world. Wiley-Blackwell.

Westman, P. (2012). "Playing with the Team": The Development of Communities of Practice in a Digital Storytelling Project. Digital Education Review, 22, 92-99.

Xu, Y., Park, H., \& Baek, Y. (2011). A New Approach Toward Digital Storytelling: An Activity Focused on Writing Self-efficacy in a Virtual Learning Environment. Educational Technology \& Society, 14(4), 181-191.

Youtube. (2015). Estadísticas: Youtube. Recuperado el 18 de 11 de 2015, de http://www.youtube.com/yt/press/es/statistics.html 